\title{
Influenza Humana A H1N1, su profilaxis y tratamiento con antivirales
}

\author{
AH1 N1 Human Influenza, Its Prophylaxis and Anti-viral Treatment \\ Mtra Dolores Zarza Arizmendi* \\ **Profesor de Carrera Asociado "C" ENEO-UNAM
}

\section{Resumen}

En el presente artículo se presentan las directrices generales que los profesionales de la salud deben conocer sobre la utilización de los antivirales en la profilaxis y tratamiento de la influenza humana tipo $\mathrm{A}(\mathrm{H} 1 \mathrm{~N} 1)$ que recientemente se presento en nuestro país, Se especifican además los criterios para la dosificación y la vía de administración de acuerdo con la edad del enfermo y del antiviral que se trate. Se hace énfasis en los casos en los que están indicados los antivirales así como aquellos en los que se requiere extremar precauciones y limitar su uso. Así mismo como el uso de medidas no farmacológicas para evitar la diseminación del virus.

Palabras clave: influenza humana tipo A (N1H1), antivirales, profilaxis, tratamiento.

\section{Abstract}

In this article, we state the general directions on AH1N1 human influenza anti-viral use, prophylaxis, and treatment. These directions were recently introduced in our country they should be known by all health professionals. For instance, dose and administrations form are specified according to age and suspected or confirmed case status, cases in which antivirals are indicated, as well as cases in which it is necessary highlighted.

Key words: AH1N1 human influenza, anti-virals, prophylaxis, treatment to extreme anti-viral precautions and/ or limit their use, are all

\section{INTRODUCCIÓN}

La influenza es una enfermedad respiratoria causada por alguno de los tres tipos de virus que se conocen: A, B y C. El tipo A se subclasifica según sus proteínas de superficie: Hemaglutinina $(\mathrm{H})$ y Neuraminidasa $(\mathrm{N})$ de estas depende su capacidad para provocar formas graves del padecimiento. El virus se clasifica en tipo A, B o C, y el subtipo A puede presentarse en hasta 144 combinaciones, desde H1N1 hasta H16N9 ya que se han detectado 16 hemaglutininas $(\mathrm{H})$ y 9 neuraminidasas $(\mathrm{N}){ }^{1}$

$\mathrm{El}$ virus de la influenza se caracteriza por tener una gran variabilidad genética, con potencial de recombinación genética entre los virus humanos y de ciertas especies de animales como aves, cerdos, tigres, entre otros. Es una enfermedad aguda, habitualmente benigna y de alta transmisibilidad que se propaga principalmente por pequeñas gotas de saliva. Desde el punto de vista de la salud pública, el de mayor impacto es el virus de la influenza tipo A, que tiene la capacidad de infectar a humanos y algunas especies de animales.

Se distinguen dos formas de presentación la estacional y la pandémica, esta última es cuando se extiende a varios países y continentes, traspasa fronteras y supera el número de casos y persiste en el tiempo. Tal es el caso de la influenza humana $A$ (H1N1) la cual es considerada en este momento como una pandemia ya que se han presentado casos casi todos los países.

Los primeros casos en México se presentaron en abril del 2009, en este mismo mes la OPS y la OMS solicitan 
a México dar seguimiento a 47 casos de neumonía atípica con complicaciones severas que ocasionaron en muchos casos la muerte del enfermo, en forma simultánea se decide enviar muestras para la tipificación del virus a Canadá y el 23 de abril se notifica que el agente causal es un nuevo virus con la capacidad de mutar y modificar su código genético situación que permitió su trasmisión de hombre a hombre, generando alarma mundial al desconocer hasta ese momento su comportamiento (transmisibilidad, virulencia etc.)

Una de las primeras interrogantes y ante la aparición de graves complicaciones respiratorias y defunciones a causa de la influenza humana A (H1N1), fue si existía un tratamiento efectivo para prevenir o tratar esta enfermedad por lo se recurrió a la experiencia en el tratamiento de la influenza estacional en la cual se administran medicamentos antivirales. En la actualidad existen cuatro: oseltamivir, zanamivir, amantadina y rimantadina. Cabe señalar que los virus de la Influenza Humana A H1N1 que se han detectado en México y en Estados Unidos son resistentes a la amantadina y a la rimantadina y a la fecha son sensibles al oseltamivir y al zanamivir.

La indicación o no de administrar antivirales con fines de prevención o tratamiento depende de varios factores pero uno de los mas importantes es el tipo de contacto que se tuvo con una persona con influenza humana $A$ H1N1 confirmado o presunto caso o un contacto cercano; también depende si el contacto se dio durante el periodo infeccioso, mismo que abarca desde el día anterior a la aparición de la enfermedad hasta los 7 días posteriores a la aparición de ésta.

Se habla de caso confirmado cuando la persona cursa con enfermedad respiratoria aguda y una infección por el virus de la influenza humana $A(H 1 N 1)$ confirmada por un laboratorio especializado a través de una o más de las pruebas de método RT-PCR en tiempo real y por cultivo viral. Un presunto caso de infección por el virus de la influenza humana A (H1N1) e cuando una persona cursa con enfermedad respiratoria aguda que fue un contacto cercano de un caso confirmado de infección por el virus durante el periodo infeccioso del caso o cuando la persona presenta síntomas de enfermedad respiratoria aguda y viajó o reside en un área en donde se han presentado casos confirmados de infecciones por el virus de la influenza humana A (H1N1).

Un contacto cercano es cuando de estuvo a una distancia de 2 metros o menos de una persona enferma que tiene un caso presunto o confirmado de infección por el virus durante el periodo infeccioso de la enfermedad. ${ }^{2}$

\section{PROFILAXIS Y TRATAMIENTO}

El uso de medicamentos antivirales para el tratamiento y profilaxis de la influenza ha sido fundamental para el control de los brotes sin olvidar la importancia que tiene el que se apliquen las medidas de prevención personales como el uso de cubrebocas, mascarillas específicas que retienen partículas virales, lavado de manos, además de las medidas de distanciamiento social como; no asistir a lugares cerrados, evitar el saludo de mano y beso entre otras.

Varios estudios han demostrado que cuando se administran antivirales la enfermedad y sus síntomas son más leves y las complicaciones graves de la influenza disminuyen. Con respecto a su efectividad, ésta es mejor si se inicia el tratamiento dentro de los 2 primeros días de la aparición de los primeros síntomas y aun después de las 48 horas de la aparición de los síntomas, en particular para los pacientes hospitalizados o personas con alto riesgo de sufrir complicaciones asociadas a esta enfermedad, aunque en estos casos existe el peligro de que la enfermedad evolucione a formas más grave y aún hasta la muerte. Es importante señalar que cuando se utilizan para prevenir la enfermedad su eficacia es del orden del 70 al $90 \%$ en adultos sanos. ${ }^{3}$

Los antivirales se usan con fines de profilaxis y para tratamiento. En el primer caso se utilizan en personas que no tienen síntomas, pero que han estado en contacto con una persona con diagnóstico confirmado de influenza humana A (H1N1). La duración de la quimioprofilaxis antiviral después de la exposición es de 10 días después de la última conocida a la influenza humana y se basa en sí la persona tuvo contacto cercano con otra que es un caso confirmado, probable o presunto de infección por este virus durante el periodo infeccioso. Cabe mencionar que los estudios han demostrado que la enfermedad se trasmite desde un día antes de que se presenten los síntomas y hasta 7 días después; aunque se ha observado que los niños pueden serlo por periodos más largos. ${ }^{4}$

Con base a lo anterior es importante considerar que si se tuvo contacto con una persona cuya enfermedad inició de 7 a más días de tener contacto no es necesaria la profilaxis. En el caso de que se vaya a tener contacto con una persona con influenza humana $A(H 1 N 1)$ se deben administrar los medicamentos antivirales durante el 
periodo potencial de exposición y continuarse durante 10 días después de la última exposición conocida y durante el periodo infeccioso del caso. Por lo tanto la profilaxis después de la exposición esta indicada en las siguientes situaciones:

- Contactos cercanos de casos confirmados, probables o presuntos que tengan un riesgo elevado de sufrir complicaciones por la influenza.

- Personal de atención médica, trabajadores de salud pública, socorristas que han tenido contacto cercano, identificado y sin protección con una persona infectada por el virus de la influenza humana A (H1N1) durante el periodo infeccioso de la persona.

La quimioprofilaxis antiviral (preexposición o posexposición) con oseltamivir o zanamivir se recomienda para las siguientes personas:

- Contactos cercanos que viven en la misma casa y han tenido contacto con un caso de infección presunta o confirmada y que tienen un riesgo alto de sufrir complicaciones por la influenza (afecciones crónicas, y ancianos).

- Niños en edad escolar que tienen un riesgo alto de sufrir complicaciones por la influenza (los que tienen ciertas afecciones crónicas) y que han tenido contacto cercano (cara a cara) con un caso de infección presunta o confirmada.

- Personas que viajan a cualquier lugar en donde los casos de influenza estén en su incidencia más alta y tienen un alto riesgo de sufrir complicaciones por la influenza.

- Personal de cuidado de la salud y trabajadores de salud pública que tuvieron contacto cercano, sin medidas de protección, con un caso de infección confirmada por el virus de la influenza humana tipo A (H1N1) durante el periodo infeccioso de la persona.

Se puede considerar realizar la quimioprofilaxis antiviral (preexposición o posexposición) con oseltamivir o zanamivir en las siguientes personas:

Cualquier personal del cuidado de la salud que tiene un alto riesgo de sufrir complicaciones por la influenza o personas que esté trabajando en un área en que se han confirmado casos de influenza humana $A(\mathrm{H} 1 \mathrm{~N} 1)$ y que esté al cuidado de pacientes con cualquier enfermedad respiratoria febril. ${ }^{5}$
Los criterios para el tratamiento con antivirales serán con base a la presencia de la triada de fiebre, dolor de cabeza y tos en un país o región donde exista un brote epidémico de influenza humana A (HIN1) independientemente que se trate de un exudado por prueba rápida a confirma. Es oportuno recordar que el lapso de tiempo donde el tratamiento es más efectivo son las primeras 48 horas post síntomas, por lo tanto no se debe esperar el resultado de la prueba confirmatoria que puede tardar varios días. En resumen el tratamiento se recomienda para:

- Las personas con casos confirmados, probables o presuntos de la influenza humana A (H1N1).

- Personas que tengan riesgo alto de sufrir complicaciones: niños menores de 5 años, adultos mayores de 65 , personas con enfermedad pulmonar crónica, con enfermedades cardiopulmonares, trastornos renales, hepáticos, hematológicos, neurológicos y metabólicos como diabetes mellitus, inmunosupresión, mujeres embarazadas y residentes de instituciones de ancianos y otros centro de cuidado de enfermedades crónicas.

Como se ha mencionado en la actualidad el virus de la influenza humana A (H1N1) es sensible a los medicamentos antivirales inhibidores de la neuraminidaza como el zanamivir y el oseltamivir. Los criterios para su uso es posible que cambien en la medida de que disponga de más información sobre su eficacia, el espectro clínico de la enfermedad, los efectos adversos y la sensibilidad antiviral.

Los medicamentos antivirales difieren en cuanto a quién puede tomarlos, la vía de administración y la dosis adecuada tanto para profilaxis como para tratamiento. A continuación se presentan los esquemas que proponen los CDC.

En el caso de los niños menores de un año de edad, aunque no existen estudios al respecto y tomando como base la experiencia en el tratamiento de la influenza estacional se recomienda profilaxis y el tratamiento con oseltamivir de acuerdo con el siguiente esquema.

No se han realizado estudios clínicos de los efectos de los antivirales durante el embarazo. Sin embargo, se ha demostrado en estudios en animales que la amantadina y rimantadina son medicamentos teratogénicos y embriotóxicos si se administran en dosis considerablemente altas. Debido a que se desconocen los efectos de los medicamentos antivirales para la influenza en las mujeres embarazadas y sus fetos, estos deben usarse durante el 
embarazo solamente si los beneficios potenciales justifican el riesgo para el embrión o feto.

En el caso de los niños es de vital importancia que no se debe suministrar aspirina o productos que contengan aspirina (p. ej. subsalicilato de bismuto-Pepto Bismol) a ningún caso presunto o confirmado de infección por el virus de la influenza humana tipo A (H1N1) que tenga 18 años o menos de edad debido al riesgo de sufrir el síndrome de Reye. Para aliviar la fiebre, se recomienda el uso de otros medicamentos antipiréticos como el acetaminofeno (paracetamol) o medicamentos antiinflamatorios no esteroideos. ${ }^{8}$

La Organización Mundial de la Salud en colaboración con los Estados Miembros, donantes y otros grupos tienen como prioridad el dotar de una reserva de emergencia a los países que carecen de antivirales o tienen muy pocos y, por añadidura, carecen de la capacidad de ob- tenerlos por sí mismos. Entre otras acciones ha dispuesto que la primera remesa de antivirales de su propia reserva se envíe a 72 países. Se ha dado prioridad a los países vulnerables, teniendo en cuenta la capacidad nacional de fabricación y compra del producto. Según sea necesario, otros países recibirán apoyo mediante las reservas de las oficinas regionales por lo que se garantiza que todos los países contaran con medicamentos antivirales suficientes para contender con esta pandemia.

Sin duda la prescripción de antivirales para la profilaxis y tratamiento de esta enfermedad son de vital importancia sobre todo si se usan en forma racional y siguiendo los protocolos establecidos por los organismos de salud nacionales e internacionales, pero lo es más el seguimiento puntual y permanente de las acciones preventivas básicas por todos conocidas.

Tabla 1. Dosis recomendadas para la medicación de antivirales en el tratamiento o la quimioprofilaxis de infecciones por el virus nuevo de la influenza A (H1N1).

\begin{tabular}{|c|c|c|c|}
\hline \multicolumn{2}{|c|}{ Agente, grupo } & Tratamiento & Quimioprofilaxis \\
\hline \multicolumn{4}{|c|}{ Oseltamivir } \\
\hline \multicolumn{2}{|l|}{ Adultos } & $\begin{array}{l}\text { cápsula de } 75 \text { mg dos veces } \\
\text { al día por } 5 \text { días }\end{array}$ & cápsula de 75 mg una vez al día \\
\hline \multirow{4}{*}{$\begin{array}{l}\text { Niños } \geq 12 \\
\text { meses }\end{array}$} & $\begin{array}{l}15 \mathrm{~kg} \text { o me- } \\
\text { nos }\end{array}$ & 60 mg por día divididos en 2 dosis & 30 mg una vez al día \\
\hline & $15-23 \mathrm{~kg}$ & 90 mg por día divididos en 2 dosis & 45 mg una vez al día \\
\hline & $24-40 \mathrm{~kg}$ & 120 mg por día divididos en 2 dosis & 60 mg una vez al día \\
\hline & $>40 \mathrm{~kg}$ & 150 mg por día divididos en 2 dosis & 75 mg una vez al día \\
\hline \multicolumn{4}{|c|}{ Zanamivir } \\
\hline Adultos & & $\begin{array}{l}\text { Dos inhalaciones de } 5 \mathrm{mg} \text { (total de } 10 \mathrm{mg} \text { ) } \\
\text { dos veces al día }\end{array}$ & $\begin{array}{l}\text { Dos inhalaciones de } 5 \mathrm{mg} \text { (total de } 10 \mathrm{mg} \text { ) } \\
\text { una vez al día }\end{array}$ \\
\hline Niños & & $\begin{array}{l}\text { Dos inhalaciones de } 5 \mathrm{mg} \text { (total de } 10 \mathrm{mg} \text { ) } \\
\text { dos veces al día (edad, } 7 \text { años o más) }\end{array}$ & $\begin{array}{l}\text { Dos inhalaciones de } 5 \mathrm{mg} \text { (total de } 10 \mathrm{mg} \text { ) } \\
\text { una vez al día (edad, } 5 \text { años o más) }\end{array}$ \\
\hline
\end{tabular}

Fuente: IDSA guidelines for seasonal influenza - Directrices en inglés de IDSA para la influenza estacional

Tabla 2. Dosis recomendadas para quimioprofilaxis antiviral en niños menores de 1 año usando Oseltamivir.

\section{Edad}

Dosis recomendada para la profilaxis de $\mathbf{1 0}$ días

\begin{tabular}{|c|c|}
\hline$<3$ meses & $\begin{array}{l}\text { No se recomienda a menos que se considere } \\
\text { la situación crítica, debido a la información limitada sobre este grupo de edad }\end{array}$ \\
\hline 3-5 meses & 20 mg una vez al día \\
\hline 6-11 meses & 25 mg una vez al día \\
\hline
\end{tabular}

Fuente: IDSA guidelines for seasonal influenza - Directrices en inglés de IDSA para la influenza estacional 
Tabla 3. Dosis recomendadas para la medicación de antivirales para niños menores de 1 año usando Oseltamivir.

\begin{tabular}{|l|l|}
\multicolumn{1}{|c|}{ Edad } & \multicolumn{1}{|c|}{ Dosis recomendada para el tratamiento de 5 días } \\
\hline$<3$ meses & $12 \mathrm{mg}$ dos veces al día \\
\hline $3-5$ meses & $20 \mathrm{mg}$ dos veces al día \\
\hline $6-11$ meses & $25 \mathrm{mg}$ dos veces al día \\
\hline
\end{tabular}

Fuente: IDSA guidelines for seasonal influenza - Directrices en inglés de IDSA para la influenza estacional

Esquema de tratamiento de los antivirales del grupo de los adamantanos para el tratamiento y prevención de la influenza de acuerdo a la edad del paciente.

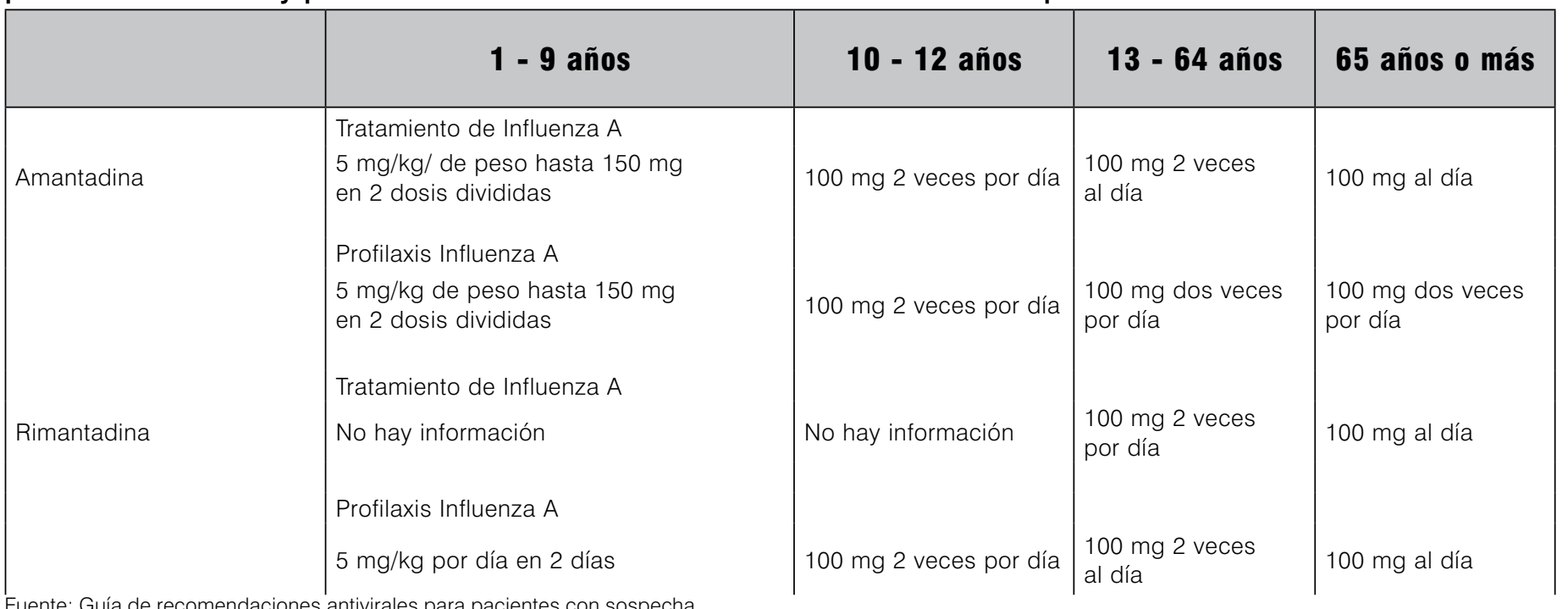

o confirmación de Influenza A H1N1 y en su contactos Centers for Disease Control (CDC), Atlanta Ca. Abril 2009.

\section{REFERENCIAS BIBLIOGRÁFICAS}

1 Dirección General de Promoción de la Salud. SSA. [Acciones básicas para mitigar la intensificación de la transmisión de la influenza]. Boletín del 24 abril, 2009. [acceso 1 junio 2009] Disponible en: www.dgepi.salud.gob.mx/SINDRO_RES/acciones.pdf

2 Centers for Disease Control and Prevention.[ Directrices provisionales sobre el uso de medicamentos antivirales en pacientes con infección por el virus nuevo de la influenza tipo A $(\mathrm{H} 1 \mathrm{~N} 1)$ y en personas que hayan tenido contacto cercano con ellos]. Boletín del 6 de mayo [acceso 4 junio 2009]disponible en:http://www.cdc.gov/ H1N1flu/espano./recomendaciones.htm

3 Centers for Disease Control and Prevention. [Las Medicinas Antivirales y la Gripe] boletín 22 de octubre 2004. [acceso 8 de junio 2009] disponible en: www.cdc.gov/flu/protect/antiviral/pdf/antiviral-sph.pdf

4 Idem
5 Secretaría de Salud, Manual de Vigilancia Epidemiológica de la Influenza, $2^{a}$. Ed. Febrero 2007. Pág. 42-48

6 Centers for Disease Control and Prevention. [Directrices provisionales para médicos sobre prevención y tratamiento de niños pequeños con infecciones por virus de influenza porcino]. Boletín 28 de Abril 2009. [acceso 17 de junio 2009] disponible en: http://www.cdc.gov

7 Centers for Disease Control and Prevention [Guía de recomendaciones antivirales para pacientes con sospecha o confirmación de Influenza A H1N1 y en sus contactos]. Boletín Abril 2009

8 Prevention and Control of Influenza. Recommendations of the Advisory Committee on Innunization Practices (Acip) 2007

\section{DIRECCIÓN PARA CORRESPONDENCIA}

Mtra. Dolores Zarza Arizmendi: mdz55@hotmail.com 